\title{
Remote sensing and GIS in hydrogeology
}

\author{
Jörn Hoffmann • Per Sander
}

\section{Introduction}

Satellites and airplanes are fascinating. The technology is still young enough for many to remember when it was not around. Airborne and spaceborne imagery have also received their share of attention as they have become better and increasingly detailed, making progress highly visible. The recent development of viewers like Google Earth has yet again amazed and inspired many people. However, as "any sufficiently advanced technology is indistinguishable from magic" (Arthur Clarke, Profiles of The Future, 1961), it is difficult for people unfamiliar with remote-sensing technology to judge what is and is not possible today. Fascinating satellite imagery frequently leads to over-expectation as to what satellite observations are feasible. However, if satellites can do so much, why should mapping groundwater flow from satellites present a problem?

To hydrogeologists, the obvious answer is that groundwater is shielded against remote measurements by complex and often poorly understood geological features. And indeed, this does present the main challenge and obstacle for applying remote-sensing techniques to solving hydrogeological problems. Consequently, adding hydrogeological meaning to remote-sensing observations involves models, assumptions and approximations.

Although there are many limitations to remote-sensing approaches to issues below ground, the typical spatial

Received: 27 September 2006 / Accepted: 17 November 2006

Published online: 12 December 2006

(C) Springer-Verlag 2006

\author{
J. Hoffmann ( \\ German Remote Sensing Data Center (DFD), \\ German Aerospace Center (DLR), \\ Münchner Str. 20, 82234, Wessling, Germany \\ e-mail: joern.hoffmann@dlr.de \\ Tel.: +49-8153-283329 \\ Fax: +49-8153-281445 \\ P. Sander \\ Ramböll Sverige AB, \\ Environmental Division, \\ Vädursgatan 6 Box 5343 40227, Göteborg, Sweden \\ e-mail: per.sander@ramboll.se
}

completeness and ease of data acquisition creates a lot of opportunities and is well worth considering in many cases. Of course, data derived from remote-sensing observations are used pervasively already, often even without remembering how they were obtained. Digital elevation models (DEMs), for example, used in almost all hydrogeological modelling, have usually been acquired from air- or spaceborne sensors.

The value of satellite remote-sensing data in groundwater assessment over the last three decades is obvious, starting with the application of Landsat MSS (multispectral scanner) data in various regional studies in the early 1970s, followed by Landsat TM (thematic mapper) and SPOT data in the 1980s. However, until fairly recently, the image data from these sensors were expensive and their acquisition and subsequent interpretation for groundwater exploration were, in many cases, limited to large donorfunded projects.

The last decade has seen a dramatic decrease in the cost of satellite imagery and the hardware and software needed for their efficient interpretation. At the same time, processing speed and data storage capacity of affordable computers have increased by many orders of magnitude. In addition, the user-friendliness of the image processing and interpretation software has developed to a level where necessary training courses can focus on a geological understanding of spectral signatures and spatial patterns on remotely sensed images rather than getting stuck in software problems.

Remote sensing is without doubt the backbone of hydrogeological reconnaissance in areas of the world where the coverage of detailed geological maps and field data is insufficient. However, even in well-mapped areas, satellite imagery, now available at a relatively low cost, will reveal structural and lithological features that previously went undetected, and which will provide an improved understanding of the hydrogeological system which, for example, can lead to a more efficient and sustainable use of groundwater resources for water supply.

This theme issue tries to outline how remote-sensing technology is brought to bear on hydrogeological science and applications already — and where there are limitations. The papers and essays contained in this theme issue can hopefully inspire the reader to look further and possibly discover new opportunities for using the powerful tools available in their own work. 


\section{A map to this issue}

The guest editors have tried to sample the wide range of issues and applications that benefit from remote-sensing observations. The topics covered range from measurement of soil moisture to modelling groundwater flow, from lineament mapping to estimating storage changes. The spatial scales also vary widely from topographic analyses at sub-metre resolutions to storage changes for entire basins. Nevertheless, the selection is far from being complete or representative.

Brunner et al. review the types of remote-sensing observations available for supporting groundwater modelling. They emphasise two ways in which they can be useful: providing model input parameters directly and constraining model calibration. Examples from Botswana and China demonstrate both of these uses. The value added by incorporating remote-sensing data is assessed and discussed.

Zahn and Conrad describe the use of remote-sensing techniques, spatial modelling and botanical mapping to identify groundwater-dependent ecosystems in order to fulfil the objectives of the National Water Act of South Africa. Remote-sensing data here proved to be essential for efficient mapping of sensitive wetlands in areas subject to intensive use of groundwater for agriculture.

Nyborg et al. demonstrate the use of very high accuracy elevation data as a tool in detailed structural geological mapping and lineament detection. The extremely detailed three-dimensional ground-surface model is used in combination with other supporting data to characterise structural features in a hydrogeological model used in the siting of a nuclear waste repository.

Robinson et al. investigate the structure of the Nubian aquifer system in southwest Egypt using synthetic aperture radar (SAR), which can penetrate a small distance into the dry surface. They identify structural features, including alluvial fans, in the SAR imagery. This information is combined with a slope map derived from a SRTM (Shuttle Radar Topography Mission) digital elevation model, and used to characterise heterogeneous recharge conditions. In the context of these structural observations, the authors interpret spatially variable groundwater salinities to illuminate groundwater flow paths.

Rhén et al. describe the investigation techniques used for hydrogeological characterisation and modelling in the intensive site investigations for a nuclear waste repository in southeastern Sweden. Various remote sensing and geophysics techniques have been integrated to define positions of potential deformation zones in the bedrock, which subsequently have been investigated by field mapping, detailed ground geophysics, drilling and hydraulic testing.

Sander gives a general overview of lineament mapping and interpretation using remote-sensing data for groundwater exploration and discusses some typical applications and limitations in semi-arid hard rock areas.

Tweed et al. demonstrate the use of various types of remote-sensing data to identify groundwater recharge and discharge areas in a high salinity- and drought-prone area with intense agricultural activity.

Leblanc et al. show how remote-sensing data and geographical information systems (GIS) can be used to define recharge and discharge areas, groundwater and surface water interaction, and paleohydrological settings as input to a regional groundwater model of a large Quaternary aquifer in central Africa.

Fernández-Prieto and Palazzo report on the European Space Agency's TIGER initiative, an attempt to coordinate research and development - using data acquired by ESA's satellite sensors - that can be brought to bear on the management of Africa's water resources.

Entekhabi and Moghaddam discuss how groundwater recharge can be estimated from remote-sensing observations of soil moisture. They present two mission concepts that would provide the necessary measurements and explain the modelling involved in estimating groundwater recharge from such observations.

Kerr provides a brief history of the evolution of the remote sensing of soil moisture conditions and argues that only low-frequency microwaves can provide adequate observations today. The author then gives a perspective on how soil moisture data acquired from space can soon improve dramatically with future missions.

Wagner et al. compare four soil-moisture datasets derived from three different satellite sensors using different retrieval algorithms. They conclude that these data can indicate trends in surface soil moisture conditions but are still inadequate to determine absolute values reliably.

Galloway and Hoffmann discuss how cases of ground displacement, observed by interferometric SAR (InSAR), are interpreted in the context of the underlying geomechanic causes to improve the understanding of exploited aquifer systems. They give examples for using InSAR-derived displacements for identifying structural controls and heterogeneity in aquifer systems, estimating storage parameters and vertical hydraulic conductivities, and for calibrating a groundwater flow model.

Bandyopadhyay et al. give an overview of the Indian satellite program and highlight how this has been exploited in different hydrogeological applications in India.

Rodell et al. use data from the Gravity Recovery and Climate Experiment (GRACE) to measure large-scale groundwater storage changes in the Mississippi River basin and major sub-basins. Effects of snow and soil moisture on the gravity signal are modelled and removed from the measured signal. The authors discuss the feasibility of using GRACE to observe groundwater storage changes in large and poorly instrumented aquifer systems.

Güntner et al. highlight the fascinating potential of using GRACE for monitoring and modelling groundwater storage changes globally, and emphasise the developments and considerations necessary to exploit this potential fully.

Fredrick et al. argue that water levels in lakes and wetlands represent the water table in their Wisconsin test 
area (USA) and calibrate a GIS-based regional groundwater flow model to surface water levels measured by the SRTM.

Minor et al. present the only paper in this issue that does not directly involve the use of remote-sensing data, although some of the data have been derived from remotely sensed images such as the DEM. The paper instead illustrates the value of GIS in combining spatial information from various sources and various scales to provide meaningful recharge estimates of a large area in western United States.

Jha and Chowdary try to identify obstacles to applying remote-sensing methods in managing groundwater resources in developing nations. After presenting past investigations and their utility, they discuss institutional and technical difficulties commonly encountered in developing countries and suggest possible ways around these.

\section{A view from afar}

A commonly voiced criticism of remote-sensing studiesnot just on hydrogeological themes - is that its potential is oversold. It is easy to get carried away by pretty pictures and visualisations that give the impression of spatially complete and accurate knowledge of some parameter. The spatial completeness and detail can be deceiving. Because the actual measurement is usually something quite different from the parameter being mapped, the models and assumptions involved in converting one to the other are often the main flaw. These assumptions may only be valid for part of the region under investigation, or only a very rough approximation. Consequently, the resulting map may be highly accurate in some areas, but utterly useless in others. Unfortunately, few images actually convey the difference. While it is important to remain critical, the observations should not be discarded just because they fail to produce reliable results some of the time.

Several authors in this issue emphasise that remotesensing data cannot replace ground-based data. The latter are often invaluable for calibrating and validating the interpretations. Satellites and planes will never be able to replace fieldwork.

Incorporating views and experience of different disciplines is essential to applying remote sensing successfully in, for example, groundwater-resource assessment. Without a good understanding of the geological conditions and hydrological properties in the area investigated, the full potential of the imagery cannot be exploited. Poor interpretations can also lead to substantial resources being spent on ground investigations at the wrong locations.

Disciplines other than geology and hydrology must often be involved when assessing water resources from remote-sensing data. Social, economical and political constraints may prove very important, and there is often a need to integrate remote-sensing data with data from an array of sources to arrive at the right decisions. In this context, geographical information systems are an ideal problem-solving environment where remote-sensing data and interpretations can be merged with discrete and continuous data from other sources to better understand relationships that may otherwise go undetected.

It is true that remote sensing cannot and will never replace information gathered in field campaigns and from the general context of the issue at hand. However, the opposite is equally true. Ground-based measurements will never be able to provide the perspective afforded by a view from above, even though the exploitation of remotesensing measurements often requires a new way of thinking about a problem, and requires us to acclimatise and to gain faith in a new set of models and assumptions. Nevertheless, surely, taking a fresh look is a good thing. 